\title{
The Therapeutic Effect of Statins on Survival of Patients with Gastrointestinal Cancer: a Review
}

\author{
Ali Olfati ${ }^{1}$, Nasroallah Moradi-kor ${ }^{2}$ \\ ${ }^{1}$ Research Center for Pharmaceutical Nanotechnology, Biomedicine Institute, Tabriz \\ University of Medical Sciences, Tabriz, Iran \\ ${ }^{2}$ Research Centre of Physiology, Faculty of Medicine, Semnan University of Medical Sciences, \\ Semnan, Iran \\ *Corresponding Author E-mail: A.olfati65@gmail.com
}

Received: 18 January 2019, Revised: 13 March 2019, Accepted: 15 March 2019

\begin{abstract}
Cancer can significantly have ruining effects on very high of human beings, social, and economic condition. Gastrointestinal (GI) cancer has been reported as one of the most prevalent cancers and the incidence rates of this disorder is increasing across the world. This review explains practical recommendations for the management and improvement of patients with GI cancer by statins. Statins, a group of lipoproteins drugs, are used in medicine to treatment of lipid disorder, hypercholesterolemia reduction and cardiovascular risk. The exact mechanisms of anticancer activity of statins are still unknown. However, in some preclinical and epidemiological studies have reported them to have anticancer properties and therapeutic consequences for GI cancer based on preclinical evidence of their including antihypoxic processes, anti-invasive, induction of growth arrest and proapoptotic, radiosensitizing, angiogenesis and inhibition metastasis. The main objectives of this review paper are: 1. Explain the importance of sickness understanding and prognostic awareness in patients with cell proliferation, induction cell apoptosis, metastasis, angiogenesis, immunity and inflammatory GI cancers receiving statins groups. 2. Explain the importance of statins therapy in low- and middle- risk patients with GI cancers.
\end{abstract}

Key words: Cancer, Gastrointestinal, Statins, Adjuvant therapy.

\author{
Abbreviations used: \\ $\mathrm{GI}=$ (gastrointestinal) \\ $\mathrm{EC}=$ (esophageal cancer) \\ $\mathrm{CRC}=($ colorectal cancer $)$ \\ HUVEC $=$ (human umbilical vein endothelial cell)
}

\section{Introduction}

Gastrointestinal (GI) cancer (including esophageal cancer (EC), gastric cancer and colorectal cancer (CRC)) has been reported as one of the most common cancers in all over the world. Although statins are broadly used to treat the GI cancer, but their 
mechanisms are still unknown. Most of the current published data have focused on statins as chemopreventive agents, but there is increasing interest in its use for treatment of GI cancer. Most suspected patients with GI cancer show advanced disorders to palliative management.

Statins (3-hydroxy-3-methylglutaryl-coenzyme A reductase inhibitors-HMG-CoA reductase inhibitors) is commonly used to treat the primarily raised cholesterol, dyslipidemias and cardiovascular disease in certain patients after surgery, chemotherapy and radiation therapy. They are known to have low side effects in clinical uses; suggesting low-side effects (Lee et al., 2014).

In turn, this medication (timing, dosage, and duration of statins therapy) can block and reduce the growth of cancer cells and promote cell survival, by interfering in inhibition of tumor cell proliferation, induction of proapoptotic, angiogenesis, immunomodulatory and inhibition metastasis in the all tissue types and cancer cell lines (Table 1). Thus we hypothesized that suspected patients who were appointed to statins treatment (especially long-term and high therapeutic concentrations) would have protective effects on GI tumor or related cancer.

This comprehensive review evaluates the complex interaction among statins therapy, improved survival and decreased morality rates in patients with GI tumor or related cancer, we next explain the importance of sickness understanding and prognostic awareness patients with GI cancer.

Table 1. Key studies describing the comprehensive anti-cancer effects of statins (as a multiple functions drugs) on gastrointestinal

\begin{tabular}{|c|c|c|}
\hline \multicolumn{2}{|c|}{ Inhibition of tumor cell proliferation } & $\begin{array}{c}\text { Kureishi et al. (2); Kato et al. (3); Cheng-Qian } \\
\text { et al. (4) }\end{array}$ \\
\hline \multicolumn{2}{|c|}{ Induction of cell apoptosis } & $\begin{array}{l}\text { Agarwal et al. (5); Ogunwobi and Beales, (6); } \\
\text { Spampanato et al. (7); De LLobet et al. (8) }\end{array}$ \\
\hline & Proangiogenic (Low-dose) & $\begin{array}{l}\text { Weis et al. (9); Assmus et al. (10); } \\
\text { Spyridopoulos et al. (11) }\end{array}$ \\
\hline Angiogenesis & $\begin{array}{l}\text { Neurodegeneration (medium- } \\
\text { dose) }\end{array}$ & Chylack et al. (12); Fildes et al. (13) \\
\hline & Angiostatic (high-dose) & Lee et al. (1) \\
\hline & ibition of metastasis & Lee et al. (1); Demierre et al. (14) \\
\hline & imatory and Immunity & $\begin{array}{c}\text { Fildes et al. (13); Pahan, (15); Poggi et al. (16); } \\
\text { Diakos et al. (17) }\end{array}$ \\
\hline & ntioxidant activity & Fildes et al. (13), Farmer, (18); LaRosa, (19) \\
\hline
\end{tabular}

\section{Treatment goals of statins on gastrointestinal cancer:}

Each section of the part of this review explains short statements, the key practical recommendations related to the section of therapeutic benefit of statins on GI cancer, followed a summary of the supporting new research documents.

Inhibition of HMG-CoA reductase by the statins may be attributed to rate-limiting step of the $L$-mevalonate pathway (necessary pathway to synthesis of cholesterol and protein prenylation) and also vital pathway for a various row of end products (such as geranylgeranyl pyrophosphate and farnesyl pyrophosphate)), make reduced levels of L-mevalonate and its downstream products that most of these product and pathway play important roles in critical cellular functions (Ras and Ras homologue) including 
membrane integrity, cell signaling (dividing cancer cells need necessary cholesterol for synthesis of cell membranes), protein synthesis (proteins are essential for regulate cell cycle, invasion, proliferation, and migration), and cell cycle progression (Chan et al., 2006, Pisanti et al., 2014). With regards to effect of statins on post-transcriptional modifications of oncoproteins ad Ras and Rho, the anti-tumour effect of statins has been accepted in various cancer cell lines (Kim et al., 2001, Park et al., 2000, Lee et al., 2006).

In trust, the improper expression of $\mathrm{HMG}-\mathrm{CoA}$ reductase could be contributed to tumorigenesis schedule in GI cancer. Subsequently, control of $L$-mevalonate pathway in GI cancer cells by the statins therapy can proceeding better regulation of tumor growth, angiogenesis and metastasis, thus, statins therapy could have positive significant influences on many vital cellular functions in GI cancer. To summarize, statins therapy does seem to improve survival and decrease morality rates in patients with GI cancer.

\section{Inhibition of tumor cell proliferation}

The permanent cross-talk between cancer cells are essential for tumor growth, tumor necrosis, incursion, inflammation, angiogenesis, and tumor metastatic spread. The antineoplastic impacts of statins have also been shown in human gastric cancer cell lines by decreased cell division on total transcriptome microarrays (Cheng-Qian et al., 2014), by inhibiting the synthesis of cholesterol and proteins protein prenylation. Also, (Cheng-Qian et al., 2014) have indicated that statins prevented the growth rate of GI cancer cells, also the weight and volume of tumours in animal, thus, chemotherapy drugs may interact with the effect of statins therapy (Wang et al., 2002). Therefore, statins treatment interfering with molecular action and reaction involved in cell signaling secretion and cell viability, and finally statins therapy could inhibit tumor cell proliferation in GI cancer.

\section{Induction cell apoptosis}

Several international studies in the field of cancer research (especially those with a stem cell or basic science focus) have indicated that induction of cell apoptosis is a one of well-established marker of suitable prognosis in many cancers. A new known mechanism is that statin drugs can interfere in gastric tract cancer and provoke apoptosis rate of GI cancer cells, and prevent angiogenesis or target mechanisms implicated in the metastatic spread of cancer (Cheng-Qian et al., 2014), by interfering in the rate-limiting step of the L-mevalonate pathway. A recent clinical experiments has indicated that the induction of apoptosis process in breast cancer cell lines with Simvastatin was associated to the enhanced pro-apoptotic BAX coupled to the decreased anti-apoptotic Bcl-2 mRNA rates (Spampanato et al., 2012). Also, another study assessing lovastatin-induced apoptosis in colon cancer cell lines associated with decreased expression of the Bcl-2 and enhanced expression of the Bax rates (Agarwal et al., 1999). To the best of our knowledge, Bcl-2 and Bax expression are generally upregulated in a broad range of human tumor cancerous and are hence can a properate candidate target in many ongoing clinical experiments for GI cancer diagnosis. 


\section{Angiogenesis}

Obviously the offensive growth of malignant tumor depends on angiogenesis. Angiogenesis is defined as a complex procedure comprising the endothelial cell movement and proliferation, and as well as endothelial cell-mediated degradation of the extracellular matrix (Lee et al., 2014). All polysteps procedure of angiogenesis are essential for cancer improvement and tumor metastasis. Based on the results of (Weis et al., 2008) in human and animal models (in vivo and in vitro studies), statins has a biphasic dose-dependent effect on angiogenesis (angiostatic effects at high therapeutic concentrations and proangiogenic effects at low therapeutic concentrations) which is lipid independent and linked with changes in inhibition of endothelial cell proliferation, induction of apoptosis and vascular endothelial growth factor signaling, and finally reversible by supplementation with geranylgeranyl pyrophosphate and Lmevalonate pathway. Therefore, the seen effects of statins prevention on angiogenesis are primarily related to the absence of $L$-mevalonate but may not be completely associated for lowering cholesterol (Weis et al., 2008).

Low-dose statins promotes angiogenesis by enhancing endothelial cell proliferation, podokinesis, and migration via activation of endothelial nitric oxide synthase (Kureishi et al., 2000), and are regarded as beneficial for treating cardiovascular diseases (Assmus et al., 2003, Spyridopoulos et al., 2004). Also low-dose statins may improve angiogenesis process, in conformation this procedure of statins treatment several investigation by reducing cholesterol levels and improving endothelial functions (Weis et al., 2008, Jang et al., 2000). Endothelial function and angiogenesis are impaired by hypercholesterolemia.

But during recent years, another outcomes of statins have been appointed which could also be attributed to angiogenesis, in addition to cell-cycle blockade (Park et al., 2001). However, statins does result in signed survival improvements (Kawata et al., 2001), and further, until now it's not reported clinical trials depends on the presence of specific resistance profiles of statins. To the best of our knowledge, this review recommends destruction of overdue increase blood vessels (angiogenesis) by statins therapy (high therapeutic concentrations) and tumors cannot grow outside a critical size or metastasis to another vital organ.

\section{Inhibition of metastasis}

Metastasis is known to have lethality effects in cancer patients and involve multiple discrete stages, such as invasion of tumor cells from the primary tumour site, intravasation into the blood or lymphatic circulation and survival in the circulation, extravasation of tumour cells at the target organ site, and the colonisation of tumour cells at the new site (Joyce et al., 2008, Yang et al., 2009, Kenific et al., 2010). (Lee et al., 2014) in an animal model indicated that the growth rate and metastasis of tumours were also significantly prevented when simvastatin was applied to treat CRC. Also, in several transgenic mice models of pancreatic cancer, the intra-peritoneal simvastatin treatment caused to delay in tumor growth and metastasis formation, by the mevalonate pathway prevention (Cao et al., 2014). For discover the exact mechanisms of anticancer activity of statins, cancer researcher must be notice the mitochondria 
multiple functions, because of the mitochondrial pathway related to $L$-mevalonate pathway.

\section{Inflammatory and Immunity}

Based on a general trend, topical inflammation to be the local immune response, which this immune response could enfold host- tumour-derived, acute-phase proteins, small inflammatory protein mediators (cytokines and chemokines), and allowing immune cells acting in the positional tumour microenvironment, and subsequently thus benefit to patients (Diakos Connie et al., 2014). It must be noticed that the tumor microenvironment, where several types of inflammatory cells in along to tumor cells and extracellular matrix proteins could have interactions with anti-tumor lymphocytes, represents an hostile place where the effector functions of natural killer and $\mathrm{T}$ cells are down-regulated indirectly by soluble factors or directly by cell-to-cell contact (Biswas et al., 2006, Korc et al., 2009).

Recently, there is good evidence for interleukin 6 (a pro-inflammatory and multifunctional cytokine) and interleukin 11 roles in the progression of cancer, particularly CRC (Guthrie et al., 2013) and GI cancer (Putoczki et al., 2013), and relationships with necrosis and local and systemic inflammatory responses. Nevertheless, a line with tumour progression, the cytokines alter phenotype and recruitment of the infiltrating immune cells. Also, preclinical studies in animal models and cell lines have reported that the tumor microenvironment seems to have an essential roles in clearing immune cells ultimately possess antitumor or tumourpromoting properties (Diakos Connie et al., 2014).

Basically in all appointed cancers, there is increasing evidence to the fundamental roles that local immune response and systemic inflammation have in recovery of tumors and survival of patients with cancer, and subsequently these inflammatory and immune response against tumor tissue are thought to have play important roles in limiting tumor cell development. Finally the knowledge about inflammatory and immunity responses could to better patient consequences. In addition to, statins are known to have strong immunomodulatory and anti-inflammatory impacts and can have vital roles in the regulation of anti-tumour immunity (Poggi et al., 2010). Therefore, statins family drugs could have been considered to have therapeutics for multiple forms of human disorders such as hypercholesterolemia reduction and cardiovascular risk, gastric cancer, inflammation, autoimmunity and neurodegeneration. Finally, the effects of statins are significantly associated with the reduced cholesterol content of cell membrane, depletion or even the disruption of cholesterol rich membrane micro-domains and/or the inhibition of small proteins such as guanosine triphosphate-binding proteins (Poggi et al., 2010), which ultimately the above reason certainly play a key roles in signal transduction in cancer cells.

\section{Esophageal cancer}

Esophageal cancer (EC) is the eighth and fifth most common cause of cancer-related death in women and men, in the all over worldwide (Jemal et al., 2011), and the incidence rates of which has increased particularly in less developing countries. A population-based cohort study in Denmark showed that the use of statins before a diagnosis of EC was related with a 19\% reduced in cancer-specific mortality (Nielsen 
et al., 2012). The multiple functions of statin drugs (antiproliferative, proapoptotic, antiangiogenic, immunomodulatory, and inhibition metastasis effects) also have been shown in EC cell lines and adenocarcinoma (Ogunwobi et al., 2008, Ye et al., 2012). Statins has a biphasic effect on EC and among clinical trials there were existence considerable heterogeneity about the effects of statins on this cancer (sixth most usual cancer in men). Data from the Q-Research database and the General Practice Research Database, also from a cohort of patients with EC, showed that a higher dose of statins (simvastatin $\geq 40 \mathrm{mg}$ or equivalent) may be more beneficial for improvement of EC than low-dose statins (Beales et al., 2012, Bhutta et al., 2012). Based on cohort study of (Alexandre et al., 2016) among subjects who used statins after a diagnosis of EC, the median survival time was 14.9 months compared with 8.1 months for nonusers. Also, in the entire cohort study, the use of statins after diagnosis was related to with a reduced risk of esophageal cancer-specific mortality and all-cause mortality.

Occasionally, based on observational studies in all suspected patients with EC during statins therapy an endoscopic surveillance must be administrated prior to definitive genetic testing (especially in child) until surgery is warranted. Basically, decisions are made based on patient's clinical circumstances in addition personal choice.

\section{Gastric cancer}

Based on our knowledge, given the well-appointed low toxicity and safety of statins drugs, and in vitro and clinical trials support a proper role for the application of statins in gastric cancer. Overall, statins (lipophilic statins including simvastatin, atorvastatin, lovastatin, fluvastatin, pitavastatin) disrupted and arrested progression of GI cancer, as shown previously in human and animal model (Lee et al., 2014, Poggi et al., 2010, Cao et al., 2011) and a meta-analysis showed a significant reduction in gastric cancer risk with statin use (Chiu et al., 2011, Singh et al., 2013). But various epidemiological studies (Agarwal et al., 1999, Graaf et al., 2004, Haukka et al., 2010) reported that ever-use of any statin (hydrophilic statins including rosuvastatin and pravastatin) did not improve outcome in patients with advanced gastric cancer.

In CRC cells, HMG-CoA reductase is quickly overexpressed, HMG-CoA reductase inhibitors decrease senescence and enhance proliferation of endothelial progenitor cells by controlling cell cycle regulatory genes (Assmus et al., 2003), and use of statins therapy could inhibit HMG-CoA reductase activity. The differences between gastric cancer and other tumors cannot be contributed to all tumours responding similarly to statins, and secondly, all statins did not the same effect (Cheng-Qian et al., 2014). Therefore, statins may have chemopreventive activity against cancer and all suspected patients with gastric cancer must be continued to receive routine oncology usual care. Finally, cancer researchers must be noticed that stage of disease and treatment with statins drugs or surgery factors that are associated with an increase in survival rates.

\section{Colorectal cancer}

CRC is the third most common malignancy and a common factor of cancer-related mortality globally (Bahrami et al., 2017). The CRC incidence rates in United States (from 2005 through 2014) declined annually by about 2 to 3\% (Siegel Rebecca et al., 2018). Decreases in CRC incidence prior to 2000 could be contributed to changes in risk factors and the use of screening, which allows to remove the premalignant lesions 
(Edwards et al., 2010). Epidemiologic investigations have shown that use of statins after CRC diagnosis is associated with a reduced risk of cancer mortality (Cardwell et al., 2014), by inhibition of endothelial cell proliferation and induction of apoptosis in CRC cell lines.

(Lee et al., 2014) have indicated that a conventional dose of statins in combination with bevacizumab could decrease the cell viability, migration, invasion, and tube formation of human umbilical vein endothelial cell (HUVEC). The culture media of the CRC cells treated with statins prevent HUVEC invasion by suppressing angiogenic mediators, including angiopoietin 2, binding immunoglobulin protein, and $\mathrm{Hsp} 90 \alpha$. Also, the combined treatment with bevacizumab and statins severely decreased the growth and metastases of xenograft tumors in comparison to bevacizumab alone. It is very important to note that researchers after statins therapy attention to signs and symptoms of myotoxicity with the administration of HMG-CoA reductase inhibitors. All suspected patients with GI cancer must be evaluated in endoscopy practices and outpatient gastroenterology for reduction in GI cancer mortality rates.

\section{Statins use and survival rates in clinical trials}

The occurrence rate of GI cancer and related disorder has been promoted in most regions of the worldwide. The gastric cancer is one of the three leading main cancers that causes death (0.7 million, 8.8\%) particularly in less developing countries due to a lack of early detection and access to treatment of facilities (50), and naturally these proportions will be rising further by 2025. In recent years, studies conducted in humans on the effect of statins on survival for some types of tumours (liver cancer, acute myeloid leukaemia and non-serous-papillary epithelial ovarian cancer) have indicated increased survival in advanced (Graf et al., 2008, Habis et al., 2014). In the Scandinavian Simvastatin Survival Study trial (Pedersen et al., 2000) and a nested case- control study from the Netherlands (Graaf et al., 2004) showed a significant reduction in the incidence of all cancers and fewer cancer-related deaths among statin users as compared with nonusers, which increased with increasing duration of use.

\section{Statins and cancer risk and prevention}

It has been reported that patients with advanced cancer cannot usually understand intent of their cancer treatment and rarely engage in discussions about their preferences for care at the end of life (Weeks et al., 2012). The incidence estimates for 2012 show that there were 32.6 million people (over the age of 15 years) alive who have had a cancer diagnosed in the previous five years (50), for example the percentage diagnosis rate in colorectum cancer was equal to be $9.7 \%$ (1.4 million) in 2012.

The early detection and diagnosis of a suspected patients with GI cancer has principal implications for management and improvement of the patients. In suspected patients with GI cancer practical testing must be done by immunohistochemical testing methods, screening for CRC test by colonoscopy or flexible sigmoidoscopy, endoscopy, magnetic resonance imaging and/or endoscopic ultrasound, and gene mutation analysis for diagnoses type of cancer in first- and second-degree relatives to control measures and GI cancer prevention globally. In addition, more recent rapid decreases (CRC incidence rates) are assumed to primarily reflect enhanced intake of 
colonoscopy, which now is the predominant screening test (Cress et al., 2006, Siegel et al., 2012, Olfati et al., 2018, Emami et al., 2017, Bayati Zadeh et al., 2015). Also, in suspected person must be done to at risk for familial GI cancer if they (i) have a known as genetic syndrome associated with GI tract. And to better consider the role of prognostic risk repair of statins drugs medications, additional observational studies applied involving chemotherapy, surgical and radiotherapy patients could be useful to diagnose whether a true additive therapeutic benefit to above therapeutic methods are apparent. Finally, the monitoring the process of GI cancer incidence could facilitate efforts for cancer treatment, control, and prevention. Also, after statins treatment (about low- and middle- risk patients), additional follow-up of these patients must be necessary to affirm a potential profit of statin use.

\section{Concluding remarks}

Based on our knowledge in this review, after statins therapy for improvement of GI cancer, hypercholesterolemia reduction and cardiovascular risk diagnosis could also be recognized, because these factors into both cancer screening and genetic risk assessment guidelines recommendations. Thus, the routine review of lipid and cardiovascular records could be helpful in specific cases where the GI cancer site is in question. If cancer researchers monitor the systemic statins treatment response, we can get useful feedback of GI cancer activity after therapeutic interventions. In conclusion, the authors of this review suggest that long-term and high therapeutic concentrations statins use have chemopreventive effects.

\section{Future perspectives}

The focuses of future clinical trial on this chronic toxicity round about the side effects of HMG-CoA reductase inhibitors should be on cell and plasma membrane function, small inflammatory protein mediators, calcium regulation, and drug interactions. Further experiments are needed to convers the underpinnings of sickness understanding in these patient, and how best to assistance them in their future care. Also future investigation must be concentrate the indicators (such as C-reactive protein) to have a role in the early diagnosis and to monitor GI cancers and autophagy system that induce by statins.

\section{Declaration of conflict of interests}

None

\section{References}

Agarwal, B, Bhendwal, S, Halmos, B, Moss, SF, Ramey, WG, Holt, PR. (1999). Lovastatin augments apoptosis induced by chemotherapeutic agents in colon cancer cells. Clin Cancer Res. 5:2223-2229.

Alexandre, L, Clark, AB, Bhutta, HY, Chan, SSM, Lewis, MPN, Hart, AR. (2016). Association Between Statin Use After Diagnosis of Esophageal Cancer and Survival: A Population-Based Cohort Study. Gastroenterol. 150:854-865. doi.org/10.1053/j.gastro.2015.12.039. 
Assmus, B, Urbich, C, Aicher, A, Hofmann, WK, Haendeler, J, Rossig, L, Spyridopoulos, I, Zeiher, AM, Dimmeler, S. (2003). HMG-CoA reductase inhibitors reduce senescence and increase proliferation of endothelial progenitor cells via regulation of cell cycle regulatory genes. Circ Res. 92:1049-1055. doi:10.1161/01.RES.0000070067.64040.7C.

Bahrami, A, Amerizadeh, F, Hassanian, SM, ShahidSales, S, Khazaei, M, Maftouh, M, GhayourMobarhan, M, Ferns, GA, Avan, A. (2017). Genetic variants as potential predictive biomarkers in advanced colorectal cancer patients treated with oxaliplatin-based chemotherapy. J Cell Physiol. 233(3):2193-2220. doi:10.1002/jcp.25966.

Bayati Zadeh, J, Moradi kor, N, Olfati, A. (2015). The Effects of Different Levels Aqueous Extract of Fenugreek (Trigonella foenum-graecum L.) on Performance and Immune Response of Laying Hens. J Essential Oil Bearing Plants. 18(6):1476-1481, DOI: 10.1080/0972060X.2014.981594.

Beales, IL, Vardi, I, Dearman, L. (2012). Regular statin and aspirin use in patients with Barrett's oesophagus is associated with a reduced incidence of oesophageal adenocarcinoma. Eur J Gastroenterol Hepatol. 24:917-923. doi: 10.1097/MEG.0b013e3283543f01.

Bhutta, HY, Alexandre, L, Clark, A, Holt, S, Lewis, MP, Hart, A. (2012). Mo1542 do statins prevent the histological subtypes of esophageal cancer? Prospective data from the UK General Practice Research Database (GPRD). Gastroenterol. 142:S-624.

Biswas, S, Criswell, TL, Wang, SE, Arteaga, CL. (2006). Inhibition of transforming growth factor- $\beta$ signaling in human cancer: targeting a tumor suppressor network as a therapeutic strategy. Clin Cancer Res. 12:4142-4146.

Cardwell, CR, Hicks, BM, Hughes, C, Murray, LJ. (2014). Statin use after colorectal cancer diagnosis and survival: a populationbased cohort study. J Clin Oncol. 32:3177-3183.

Cao, Z, Fan-Minogue, H, Bellovin, DI, Yevtodiyenko, A, Arzeno, J, Yang, Q, Gambhir, SS, Felsher, DW. (2011). MYC phosphorylation, activation, and tumorigenic potential in hepatocellular carcinoma regulated by HMG-CoA reductase. Cancer Res. 71:2286-2297. doi:10.1158/0008-5472.CAN-10-3367.

Chan KK, Oza AM, Siu LL. (2003). The Statins as Anticancer Agents. Clin Cancer Res. 9(1):109.

Cheng-Qian, Y, Xin-Jing, W, Wei-Xinbing, Zhuang-Lei G, Hong-Peng Z, Songde X, Pei-Lin W. (2014). Lovastatin inhibited the growth of gastric cancer cells. Hepatogastroenterol. 61:1-4. doi:10.1200/JC0.2013.54.4569.

Chiu, HF, Ho, SC, Chang, CC, Wu, TN, Yang, CY. (2011). Statins are associated with a reduced risk of gastric cancer: a population-based case-control study. Am J Gastroenterol. 106:20982103. doi:10.1038/ajg.2011.277. 
Cress, RD, Morris, C, Ellison, GL, Goodman, MT. (2006). Secular changes in colorectal cancer incidence by subsite, stage at diagnosis, and race/ethnicity, 1992-2001. Cancer. 107(suppl 5):1142-1152. doi.org/10.1002/cncr.22011.

Chylack, LT Jr, Mantell, G, Wolfe, JK, Friend, J, Rosner, B. (1993). Lovastatin and the Korc, human lens; results of a two year study. Optom Vis Sci. 70:937-943.

De LLobet, LI, Baro, M, Mesia, R, Balart, J. (2014). Simvastatin enhances the effects of radiotherapy and cetuximab on a cell line $(\mathrm{FaDu})$ derived from a squamous cell carcinoma of head and neck. Trans Oncol. 7:513-522. doi:10.1016/j.tranon.2014.02.008.

Demierre, MF, Higgins, PD, Gruber, SB, Hawk E, Lippman SM. (2005). Statins and cancer prevention. Nat Rev Cancer. 5:930-942. doi:10.1038/nrc1751.

Diakos Connie, I, Charles Kellie, A, McMillan Donald, C, Clarke Stephen, J. (2014). Cancerrelated inflammation and treatment effectiveness. Lancet Oncol. 15(11):e493-503. doi:10.1016/S1470-2045(14)70263-3.

Edwards, BK, Ward, E, Kohler, BA, Eheman, C, Zauber, AG, Anderson, RN, Jemal, A, Schymura, MJ, Lansdorp-Vogelaar, I, Seeff, LC, van Ballegooijen, M, Goede, SL, Ries, LA. (2010). Annual report to the nation on the status of cancer, 1975-2006, featuring colorectal cancer trends and impact of interventions (risk factors, screening, and treatment) to reduce future rates. Cancer. 116:544-573. doi:10.1002/cncr.24760.

Emami, S, Olfati, A. (2017). Effects of Dietary Supplementing of Spirulina Platensis and Chlorella Vulgaris Microalgae on Hematologic Parameters in Streptozotocin- Induced Diabetic Rats. Iran J Ped Hematol Oncol. 7(3):163-170.

Farmer JA. (2000). Pleiotropic effects of statins. Curr Atherosclero Rep. 2:208-217. doi:10.1146/annurev.pharmtox.45.120403.095748.

Fildes, JE, Shaw, SM, Williams, SG. Yonan, N. (2009). Potential immunologic effects of statins in cancer following transplantation. Cancer Immunol Immunother. 58:461-467. doi:10.1007/s00262-008-0541-2.

Graaf, MR, Beiderbeck, AB, Egberts, AC, Richel, DJ, Guchelaar, HJ. (2004). The risk of cancer in users of statins. J Clin Oncol. 22:2388-2394. doi:10.1200/JC0.2004.02.027.

Graf, H, Jüngst, C, Straub, G, Dogan, S, Hoffmann, RT, Jakobs, T, Reiser, M, Waggershauser, T, Helmberger, T, Walter, A, Walli, A, Seidel, D, Goke, B, Jüngst D. (2008). Chemoembolization combined with pravastatin improves survival in patients with hepatocellular carcinoma. Digestion. 78:34-38. doi: 10.1159/000156702.

Guthrie, GJ, Roxburgh, CS, Horgan, PG, McMillan, DC. (2013). Does interleukin-6 link explain the link between tumour necrosis, local and systemic inflammatory responses and outcome in patients with colorectal cancer? Cancer Treat Rev. 39:89-96. 10.1016/j.ctrv.2012.07.003.

Habis, M, Wroblewski, K, Bradaric, M, Ismail, N, Yamada, SD, Litchfield, L, Lengyel, E, Romero, IL. (2014). Statin therapy is associated with improved survival in patients with 
non-serous-papillary epithelial ovarian cancer: a retrospective cohort analysis. PLoS One. 9:e104521. doi:10.1371/journal.pone.0104521.

Haukka, J, San kila, R, Klaukka, T, Lonnqvist, J, Niskanen, L, Tanskanen, A, Wahlbeck, K, Tiihonen, J. (2010). Incidence of cancer and statin usage-record linkage study. Int J Cancer. 126:279-284. doi:10.1002/ijc.24536.

Jang, JJ, Ho, HK, Kwan, HH, Fajardo LF, Cooke JP. (2000). Angiogenesis is impaired by hypercholesterolemia: role of asymmetric dimethylarginine. Circulation. 102:1414-1419.

Jemal A, Bray F, Center MM, Ferlay J, Ward E, Forman D. (2011). Global cancer statistics. CA Cancer J Clin. 61:69-90. doi:10.3322/caac.20107.

Joyce, JA, Pollard, JW. (2008). Microenvironmental regulation of metastasis. Nat Rev Cancer. 9:239-52. doi:10.1038/nrc2618.

Kato, S, Smalley, S, Sadarangani, A, Chen-Lin, K, Oliva, B, Brañes, J, Carvajal, J, Gejman, R, Owen, GI, Cuello, M. (2010). Lipophilic but not hydrophilic statins selectively induce cell death in gynaecological cancers expressing high levels of HMGCoA reductase. J Cell Mol Med. 14:1180-1193. doi:10.1111/j.1582-4934.2009.00771.x.

Kawata, S, Yamasaki, E, Nagase, T, Inui, Y, Ito, N, Matsuda, Y, Inada, M, Tamura, S, Noda, S, Imai, Y, Matsuzawa, Y. (2001). Effect of pravastatin on survival in patients with advanced hepatocellular carcinoma. A randomized controlled trial. Br J Cancer. 84:886-91. doi:10.1054/bjoc.2000.1716.

Kenific, CM, Thorburn, A, Debnath, J. (2010). Autophagy and metastasis: another doubleedged sword. Curr Opinion Cell Biol. 22:241-5. doi:10.1016/j.ceb.2009.10.008.

Kim, WS, Kim, MM, Choi, HJ, Yoon, SS, Lee, MH, Park, K, Park, CH, Kang, WK. (2001). Phase II study of high-dose lovastatin in patients with advanced gastric adenocarcinoma. Invest New Drugs. 19:81-83.

Korc, M, Friesel, RE. (2009). The role of fibroblast growth factors in tumor growth. Curr Cancer Drug Targets. 5:639-651.

Kureishi, Y, Luo, Z, Shiojima, I, Bialik A, Fulton D, Lefer DJ, Sessa WC, Walsh K. (2000). The HMG-CoA reductase inhibitor simvastatin activates the protein kinase akt and promotes angiogenesis in normocholesterolemic animals. Nat Med. 6:1004-1010. doi:10.1038/79510.

LaRosa JC. (2001). Pleiotropic effects of statins and their clinical significance. Am J Cardiol. 88:291-293.

Lee, SJ, Lee, I, Lee, J, Park, C, Kang, WK. (2014). Statins, 3-hydroxy-3-methylglutaryl coenzyme A reductase inhibitors, potentiate the anti-angiogenic effects of bevacizumab by suppressing angiopoietin2, $\mathrm{BiP}$, and Hsp90a in human colorectal cancer. Br J Cancer. 111(3):497-505. doi:10.1038/bjc. 
Lee, J, Lee, I, Park, C, Kang, WK. (2006). Lovastatin-induced RhoA modulation and its effect on senescence in prostate cancer cells. Biochem Biophys Res Commun. 339:748-754. doi:10.1016/j.bbrc.2005.11.075.

Nielsen SF, Nordestgaard BG, Bojesen SE. (2012). Statin use and reduced cancer-related mortality. N Engl J Med. 367:1792-1802.

Ogunwobi, 00, Beales, IL. (2008). Statins inhibit proliferation and induce apoptosis in Barrett's esophageal adenocarcinoma cells. Am J Gastroenterol. 103:825-837. doi:10.1111/j.1572-0241.2007.01773.x.

Olfati, A, Moghaddam, G, Rafat Khafar, K, Mojtahedin, A, Abdolahzadeh, A. (2018). Role of follicle-stimulating hormone and estradiol benzoate in recovering spermatogenesis in tamoxifen-injured rats. Asian Pacific J Reprod. 7(6):248-253. doi: 10.4103/23050500.246342 .

Pahan, K. (2006). Lipid-lowering drugs. Cell Mol Life Sci. 63:1165-1178. doi:10.1007/s00018-005-5406-7.

Park, C, Lee, I, Kang, WK. (2001). Lovastatin-induced E2F-1 modulation and its effect on prostate cancer cell death. Carcinogenesis. 22:1727-1731.

Pedersen, TR, Wilhelmsen, L, Faergeman, O, Strandberg, TE, Thorgeirsson, G, Troedsson, L, Kristianson, J, Berg, K, Cook, TJ, Haghfelt, T, Kjekshus, J, Miettinen, T, Olsson, AG, Pyörälä, K, Wedel, H. (2000). Follow-up study of patients randomized in the Scandinavian Simvastatin Survival Study (4S) of cholesterol lowering. Am J Cardiol. 86:257-262.

Pisanti S, Picardi P, Ciaglia E, D'Alessandro A, Bifulco M. (2014). Novel prospects of statins as therapeutic agents in cancer. Pharmacol Res. 88:84-98. doi:10.1016/j.phrs.2014.06.013.

Poggi, A, Musso, A, Boero, S, Canevali, P, Zocchi Maria, R. (2010). Statins as Either Immunomodulators or Anti-Cancer Drugs: Functional Activities on Tumor Stromal Cells and Natural Killer Cells. Anti-Inflammatory \& Anti-Allergy Agents in Medicinal Chemistry. 9:8292. doi:10.2174/187152310790711719.

Putoczki, TL, Thiem, S, Loving, A, Busuttil, RA, Wilson, NJ, Ziegler, PK, Nguyen, PM, Preaudet, A, Farid, R, Edwards, KM, Boglev, Y, Luwor, RB, Jarnicki, A, Horst, D, Boussioutas, A, Heath, JK, Sieber, OM, Pleines, I, Kile, BT, Nash, A, Greten, FR, McKenzie, BS, Ernst, M. (2013). Interleukin-11 is the dominant IL-6 family cytokine during gastrointestinal tumorigenesis and can be targeted therapeutically. Cancer Cell. 24:257-71. doi:10.1016/j.ccr.2013.06.017.

Siegel Rebecca, L, Miller Kimberly, D, Ahmedin, J. (2018). Cancer Statistics. 2018. Ca Cancer J Clin. 68:7-30. doi:10.3322/caac.21442.

Siegel, RL, Ward, EM, Jemal, A. (2012). Trends in colorectal cancer incidence rates in the United States by tumor location and stage, 1992-2008. Cancer Epidemiol Biomarkers Prev. 21:411-416. 
Singh, PP, Singh, S. (2013). Statins are associated with reduced risk of gastric cancer: a systematic review and meta-analysis. An Oncol. 24:1721-1730. doi:10.1093/annonc/mdt150.

Spampanato, C, De Maria, S, Sarnataro, M, Giordano, E, Zanfardino, M, Baiano, S, Cartenì, M, Morelli, F. (2012). Simvastatin inhibits cancer cell growth by inducing apoptosis correlated to activation of Bax and down-regulation of BCL-2 gene expression. Int J Oncol. 40:935-41.

Spyridopoulos, I, Haendeler, J, Urbich, C, Brummendorf, TH, Oh, H, Schneider, MD, Zeiher, AM, Dimmeler, S. (2004). Statins enhance migratory capacity by upregulation of the telomere repeat-binding factor TRF2 in endothelial progenitor cells. Circulation. 110:31363142. doi:10.1161/01.CIR.0000142866.50300.EB.

Wang, W, Collie-Duguid, E, Cassidy, J. (2002). Cerivastatin enhances the cytotoxicity of 5fluorouracil on chemosensitive and resitant colorectal cancer cell lines. FEBS Lett. 531:415420.

Weis, M, Heeschen, C, Glassford, AJ, Cooke, JP. (2002). Statins Have Biphasic Effects on Angiogenesis. Circulation. 105:739-745.

Weeks, JC, Catalano, PJ, Cronin, A, Finkelman, MD, Mack, JW, Nancy L. Keating, NL, Schrag, D. (2012). Patients' expectations about effects of chemotherapy for advanced cancer. $N$ Engl J Med. 367:1616-1625.

WHO. Latest world cancer statistics Global cancer burden rises to 14.1 million new cases in 2012: Marked increase in breast cancers must be addressed. 2013.

Yang, Z, Yang, D, Xie, L, Sun, Y, Huang, Y, Sun, H, Liu, P, Wu, Z. (2009). Treatment of metastatic spinal tumors by percutaneous vertebroplasty versus percutaneous vertebroplasty combined with interstitial implantation of 125I seeds. Acta Radiologica. 50:1142-8.

Ye F, Zhang GH, Guan BX, Xu, XC. (2012). Suppression of esophageal cancer cell growth using curcumin, (-)-epigallocatechin-3-gallate and lovastatin. World J Gastroenterol. 18:126135. doi:10.3748/wjg.v18.i2.126.

How to cite this article: Ali Olfati, Nasroallah Moradi-kor, The Therapeutic Effect of Statins on Survival of Patients with Gastrointestinal Cancer: a Review. International Journal of Advanced Biological and Biomedical Research, 2019, 7(3), 191-203. Link: http://www.ijabbr.com/article 34662.html 